\title{
THE MUCOSA OF THE SMALL INTESTINE
}

\author{
R. Holmes, M.Sc., M.B., Ph.D.,* \\ D. O’B. Hourihane, M.B. D.C.P., M.R.C.P.I., $†$ \\ C. C. Воотн, M.D., M.R.C.P. \\ The Postgraduate Medical School of London, W.12
}

THE mucosa of the small intestine is intimately concerned with digestive processes and it rapidly destroys itself after the death of the organism which it serves. In studies of the histopathology of human intestinal mucosa this rapid postmortem autolysis has considerably limited progress, for until recently it was only possible to obtain satisfactory histological preparations either when necropsy was rapidly performed (Manson-Bahr, 1915; Adlersberg and Schein, 1947) or at laparotomy (Paulley, 1954). Such observations, however, demonstrated that abnormalities of the intestinal mucosa might be present in patients suffering from intestinal malabsorption syndrome and contradicted Thaysen's view that any changes found in the intestinal mucosa in tropical sprue or idiopathic steatorrhœa were due only to postmortem autolysis (Thaysen, 1932).

The introduction in recent years of satisfactory methods for obtaining biopsies of small intestinal mucosa (Shiner, 1956; Crosby and Kugler, 1957; Brandborg, Rubin and Quinton, 1959; Baker and Hughes, 1960; Flick, Quinton and Rubin, 1961) has confirmed the importance of mucosal abnormalities in patients with cœliac disease, idiopathic steatorrhœa and tropical sprue and has led to considerable advances in knowledge of the histopathology of these conditions (Doniach and Shiner, 1957; Sakula and Shiner, 1957; Butterworth and Perez-Santiago, 1958; Smith, Sprinz, Crosby and Sullivan, 1958; Rubin, Brandborg, Phelps and Taylor, r96oa; Fone, Cooke, Meynell, Brewer, Harris and Cox, 1960; Girdwood, Delamore and Wynn Williams, 1961). These mucosal abnormalities may be recognized when biopsies are examined directly at relatively low magnification under a dissecting microscope (Rubin, Brandborg, Phelps and Taylor, 1960a; Holmes, Hourihane and Booth, 196r) as well as

\footnotetext{
* Present address: The Royal Infirmary, Manchester, 13 .

$\dagger$ Present address: The London Hospital, Whitechapel, London, E.r.
}

by conventional histological techniques and electron microscopy.

The purpose of this paper is to describe the appearances of the intestinal mucosa in health and in the two conditions in which intestinal biopsy is of greatest diagnostic value in temperate climates, cœliac disease and idiopathic steatorrhœa. We have used the term 'idiopathic steatorrhœa' to describe those patients in whom malabsorption first presents in adult life, in whom there is no anatomical, hepatic or pancreatic cause for steatorrhœe and who have no history suggesting cœliac disease in childhood. The biopsies which are illustrated in the figures were obtained using the Crosby biopsy capsule.

\section{Normal Appearances Fejunum}

Viewed under the dissecting microscope, freshlyobtained normal jejunal mucosa is remarkably beautiful. When biopsy samples are examined in this way, the shape and appearance of the villi are seen to vary considerably in different individuals. Examples of the different dissecting microscope appearances of biopsies from twonormal subjects are illustrated in Figs. Ia and 2a; the corresponding histological sections are shown in Figs. $I b$ and $2 b$.

Fig. Ia shows the characteristic appearances of a normal jejunal biopsy. The villi project like long fingers from the mucosa and the blood vessels are easily seen through the transparent layer of columnar cells which cover them. However, although these long finger-like projections are characteristic of the biopsies from many control subjects, in others the villi are different, being broad, flat and leaf shaped. Such villi are shown in Fig. 2a. These flat, leaf-shaped villi frequently mingle with those illustrated in Fig. ra, but sometimes the entire mucosa is composed of this type of villus and occasionally these leaves appear to coalesce to form distinct ridges within an otherwise villous mucosa. This appearance is com- 


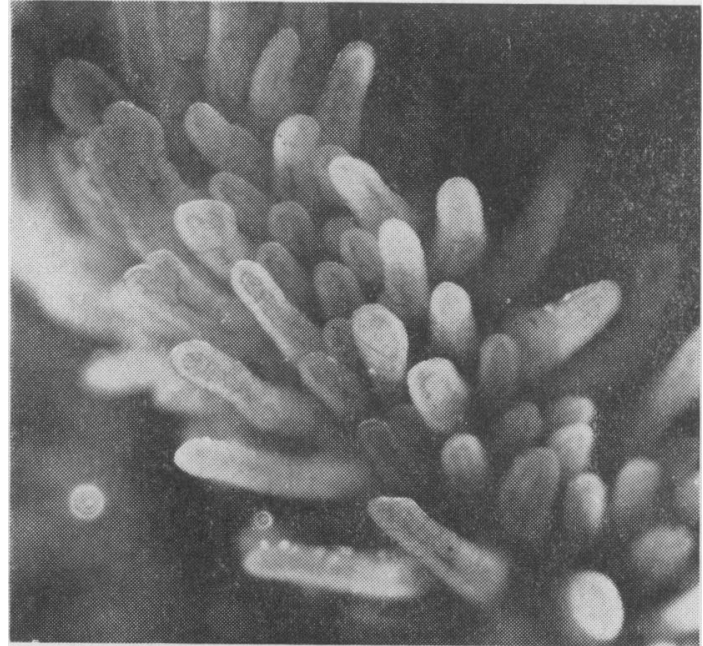

FIG. IA.-Dissecting microscope appearance of normal jejunal mucosa $(\times 25)$. The histological section of this specimen is shown in Fig. $\mathrm{rb}$.

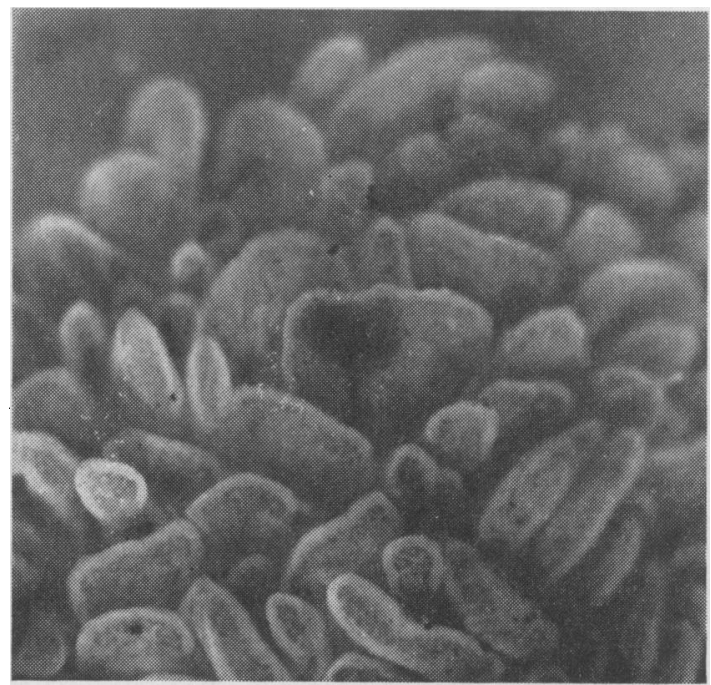

FIG. 2A.-Dissecting microscope appearance of normal jejunal mucosa showing leaf-shaped villi $\left(\begin{array}{l}x \\ 25\end{array}\right)$. The histological section of this specimen is shown in Fig. 2b.

monly seen in specimens obtained from the duodenum.

Single histological sections of normal biopsies do not reveal the differences in villus shape shown under the dissecting microscope. Figs. Ib and $2 b$ illustrate the histological sections taken from the biopsies shown in Figs. Ia and 2a. There is no significant difference between these two mucosæ when examined by conventional microscopy.

Histologically, normal villi are long and slender

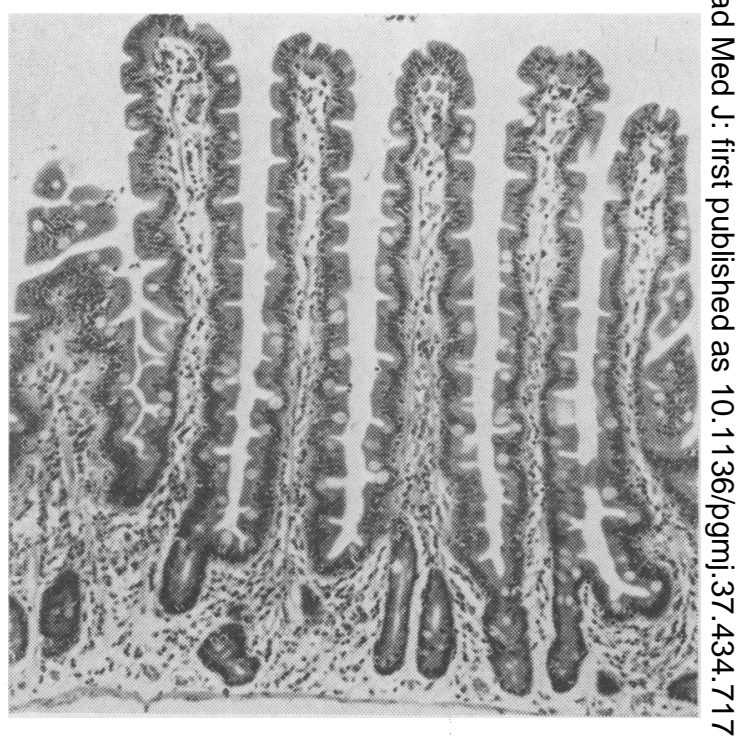

FIG. IB.-Histological section of jejunal mucosa showno in Fig. Ia.

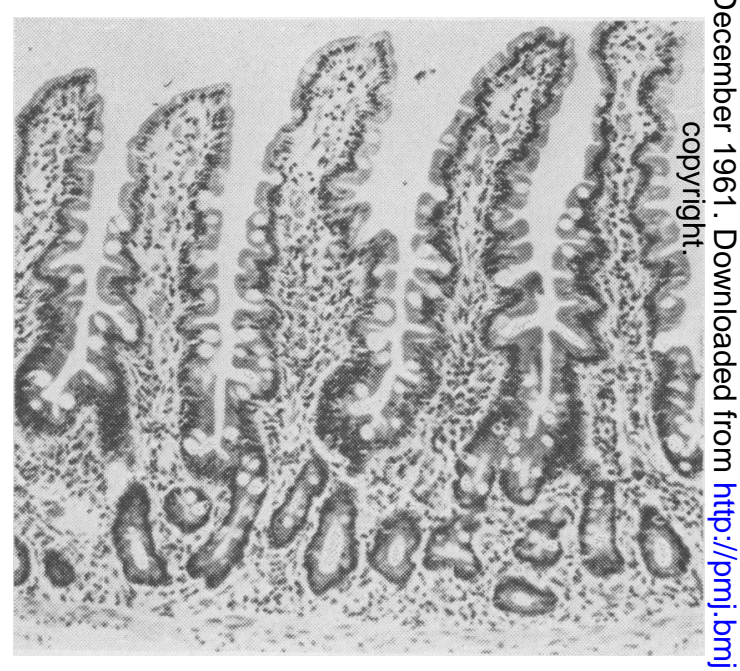

FIG. 2B.- - Histological section of jejunal mucosa shown in Fig. $2 a$.

\section{을}

윽

(Figs. Ib and $2 \mathrm{~b}$ ), varying in height between $320 \mu \mathrm{D}$ and 5 10 $\mu$, and they project from a thin glandular layer whose thickness normally measures between $120 \mu$ and $265 \mu$ (Shiner and Doniach, 1958). Under higher magnification the 'brush' border of the $N$ epithelial cells, first described by Brettauer andw Steinach (1857), may be seen. Examination of this 'brush' border by electron microscopy haso revealed that it is composed of rows of fine rod-like processes packed closely together like the posts in ? a palisade (Haubrich, Watson, O'Driscoll and Valentine, 1959; Zetterquist and Hendrix, 1960; 


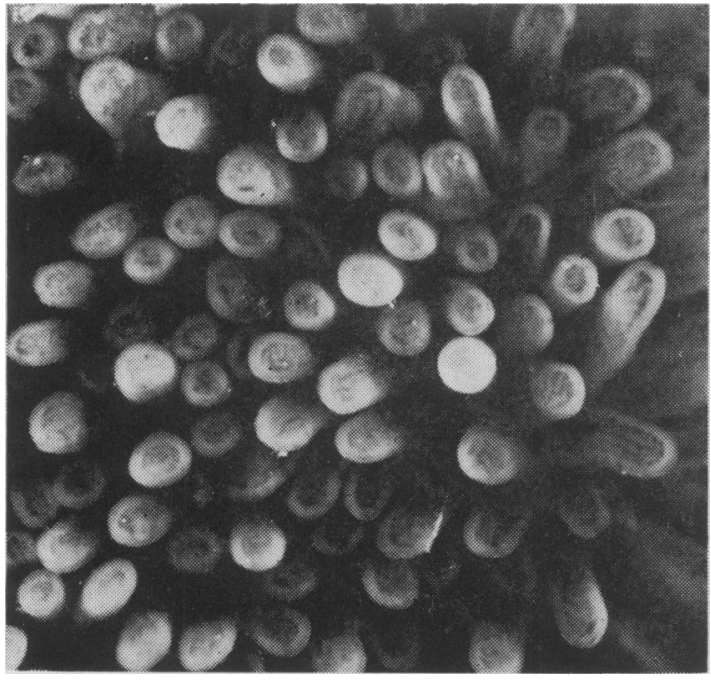

FIG. 3A.-Dissecting microscope appearance of normal ileal mucosa ( $\times 25)$. The histological section of this specimen is shown in Fig. $3 \mathrm{~b}$.

Hartman, Butterworth, Hartman, Crosby and Shirai, 1960; Padykula, Strauss, Ladman and Gardner, 196I). These processes are termed microvilli.

\section{Ileum}

The appearance of normal ileum obtained by biopsy differs very little from that of the jejunum. An example of normal ileal mucosa is shown in Fig. 3 ( $a$ and $b$ ).

Under the dissecting microscope the long, slender finger-like villi are similar to those seen in the jejunum (Fig. 3a). Leaf-shaped villi may occur in this region, but have been seen less often than in the more proximal regions of the small intestine. Histologically, the villi of the ileum are sometimes rather plumper than those usually seen in the jejunum (Fig. $3 \mathrm{~b}$ ).

\section{Cœliac Disease and Idiopathic Steatorrhœea Fejunum}

Jejunal biopsies obtained from patients with cœliac disease or idiopathic steatorrhœa are strikingly different from those of normal subjects. There is, however, a considerable variation in the appearances of biopsies in different patients and these differences are apparent both under the dissecting microscope and on conventional microscopy. We have previously classified the different dissecting-microscope appearances of biopsies from patients with cœliac disease or idiopathic steatorrhœa as either 'flat' or ' convoluted' (Holmes, Hourihane and Booth, I96r).

- Flat' Mucosa. Examples of the dissecting-

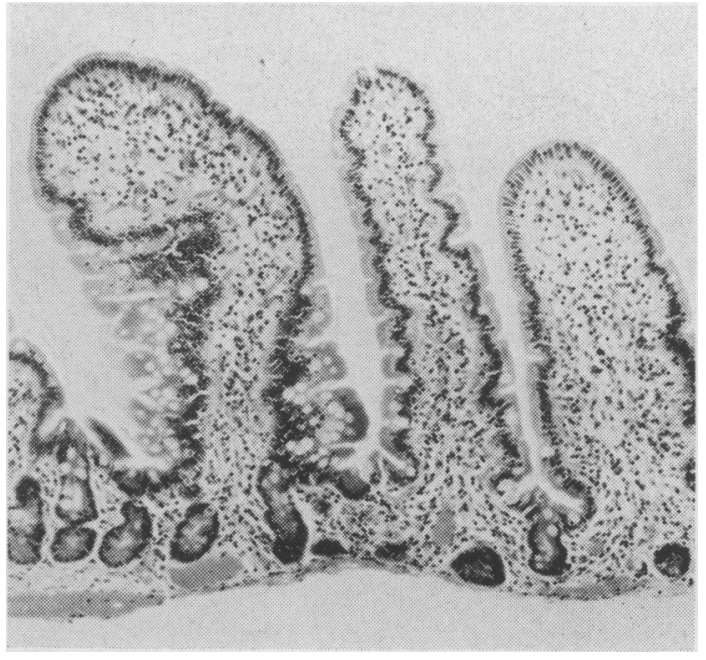

FIG. 3B.-Histological section of normal ileal mucosa shown in Fig. 3a.

microscope appearances of two varieties of the ' flat' type of mucosa are shown in Figs. $4 a$ and $5 \mathrm{a}$; the corresponding histological sections are illustrated in Figs. $4 \mathrm{~b}$ and $5 \mathrm{~b}$.

In some patients the jejunal mucosa under the dissecting microscope is entirely flat and featureless (Fig. 4a). Disorganized blood vessels may be seen through the epithelium. Histologically, there is complete loss of villi (Fig. 4 b), but the glandular layer of the mucosa is invariably thickened, measuring more than $300 \mu$ (Doniach and Shiner, 1957). This appearance has been termed subtotal villous atrophy by Doniach and Shiner (1957). Under higher magnification the epithelial cells may be seen to be thin; the striated border is often absent and electron microscopy reveals gross disorganization and loss of the microvilli (Zetterquist and Hendrix, 1960; Hartman and others, 1960; Padykula and others, 1961).

In other patients the dissecting microscope shows a similarly flat mucosa, but instead of the featureless appearance shown in Fig. $4^{a}$ the mucosa may be divided by grooves into round or hexagonal shapes, the whole mucosa appearing like a mosaic or crazy pavement (Fig. 5a). Histological sections also show the flat mucosa and, in addition, the deep grooves between the mosaic may be recognized (Fig. 5 b).

Clinically, these ' flat' biopsies are usually seen in children or adult patients with cœliac disease. Of patients who develop symptoms of idiopathic steatorrhœa in later life, those who present with diarrhœa and other gastrointestinal symptoms usually also have a 'flat' mucosa.

'Convoluted' mucosa. Examples of the dis- 


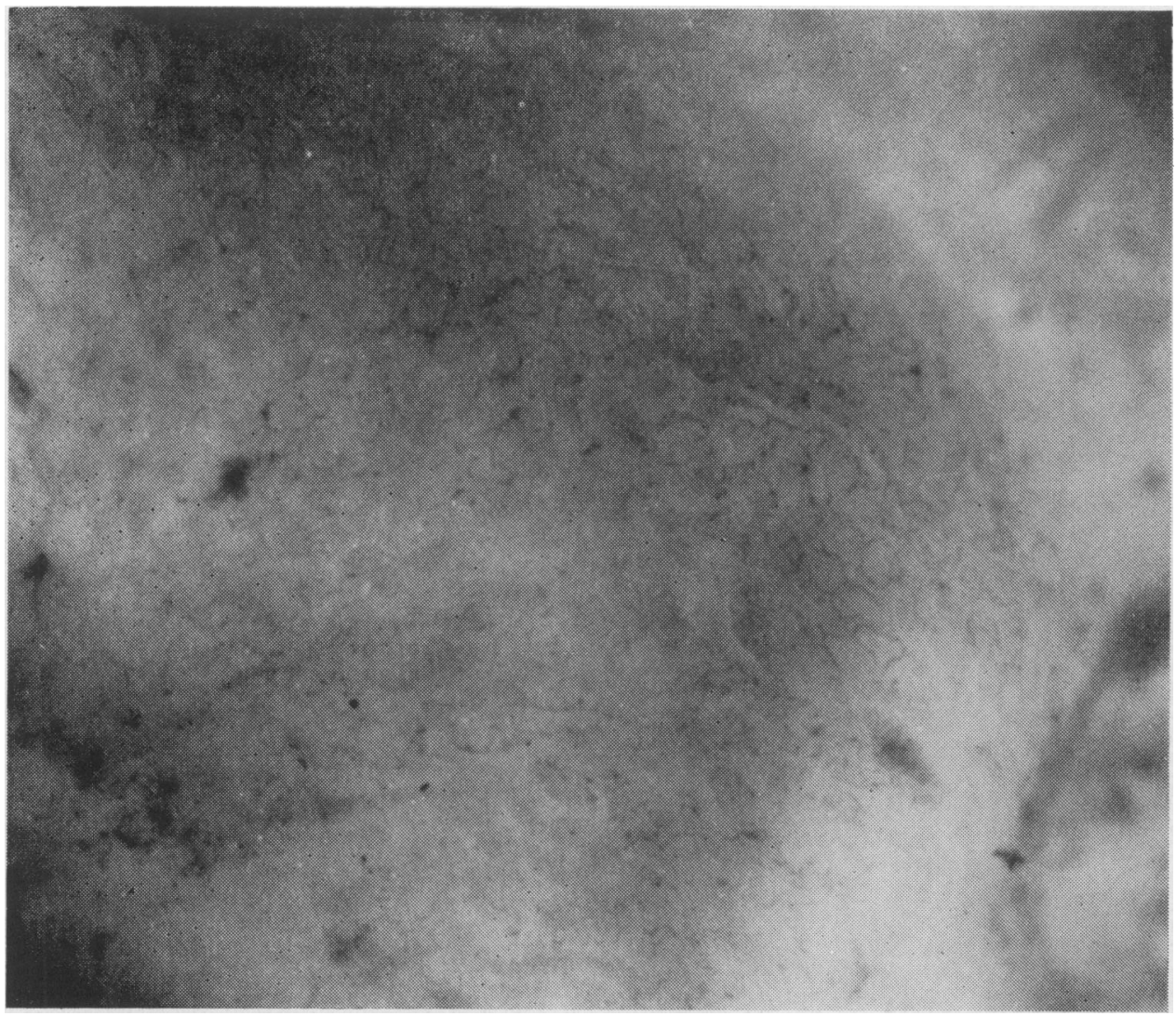

Fig. 4A.-Dissecting microscope appearance of jejunum showing 'flat' mucosa $(\times 40)$. The histological section of this specimen is shown in Fig. $4 \mathrm{~b}$.

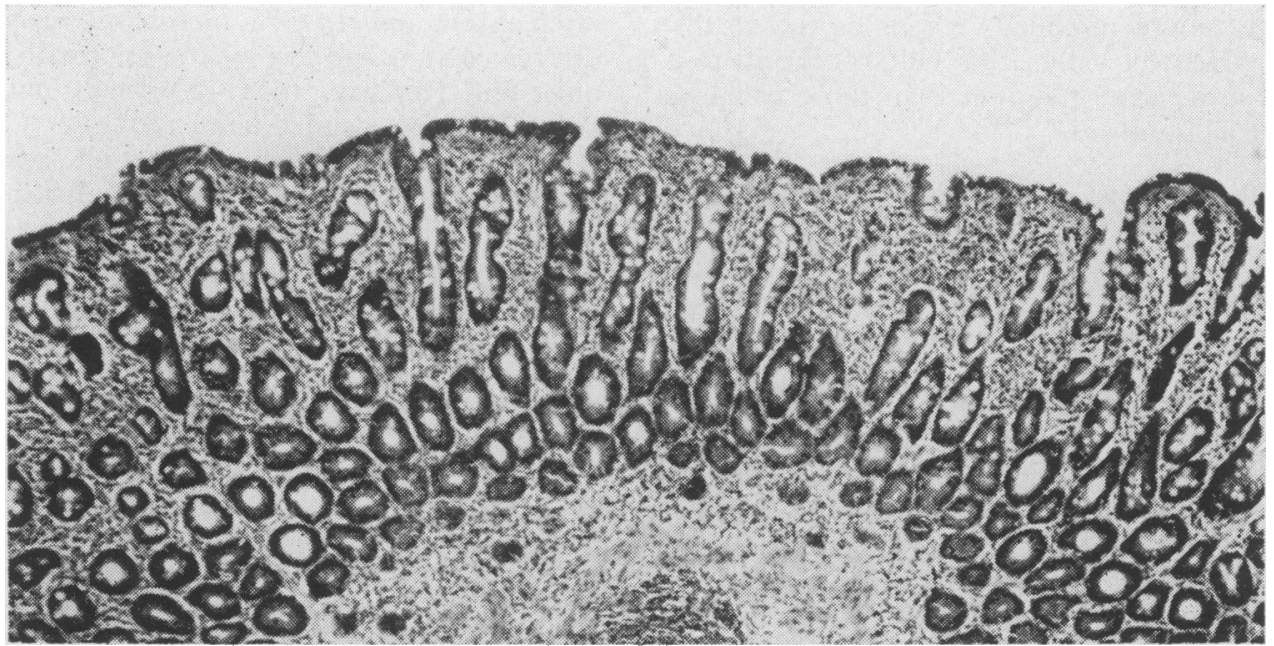

Fig. 4B.-Histological section of ' flat' mucosa shown in Fig. 4a. 


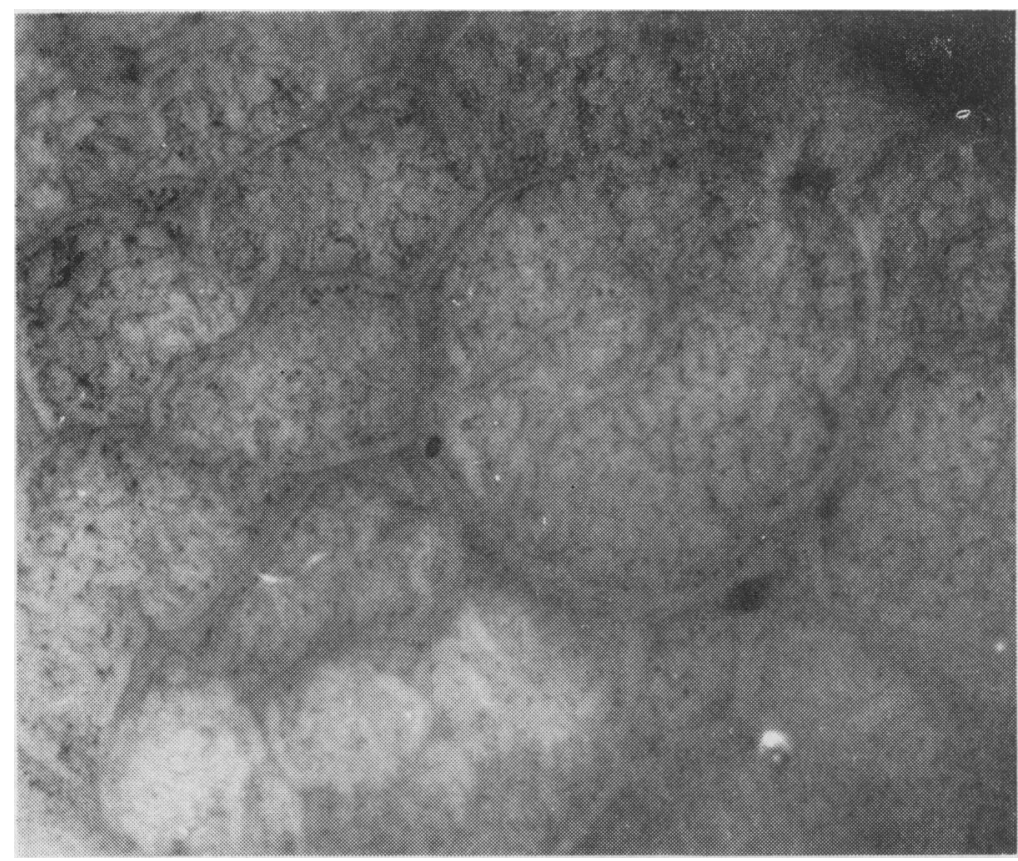

Fig. 5A.-Dissecting microscope appearance of jejunum showing 'flat' mucosa arranged in a mosaic pattern $(\times 30)$. The histological section of this specimen is shown in Fig. 5 b.

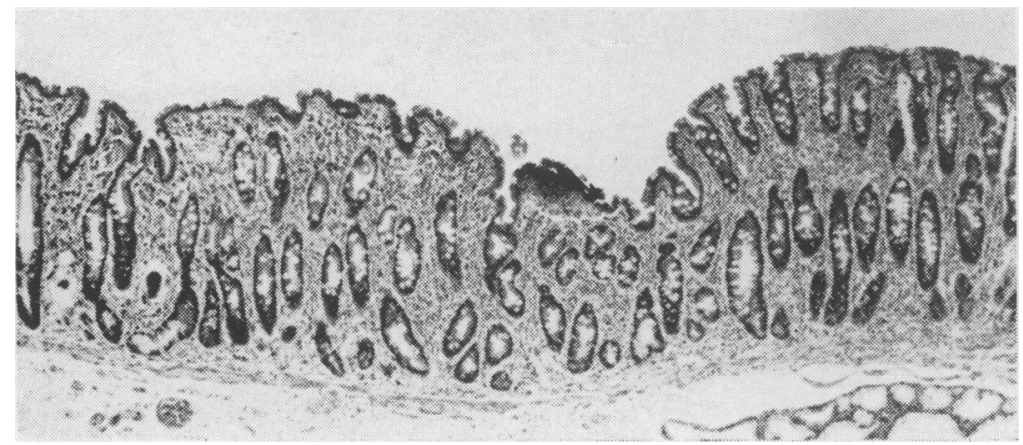

FIG. "flat, mucosa shown in Fig. 5 Histological section of

secting-microscope appearances and histological section of this type of mucosa are shown in Figs. $6 \mathrm{a}$ and $\mathrm{b}$.

Fig. 6a illustrates the dissecting-microscope appearance. In contrast to the biopsies shown in Figs. $4^{a}$ and $5 a$, this mucosa is not flat. No true villi are present, but the entire mucosa is arranged in a series of ridges and whorls reminiscent of the convolutions of the brain. Histologically, single sections through such mucosæ show what appear to be short, thick, stunted 'villi' (Fig. 6b), contrasting with the flat appearances seen in Figs. $4 \mathrm{~b}$ and $5 \mathrm{~b}$. This appearance has been termed partial villous atrophy by Shiner and Doniach (1958). Other workers have referred to these abnormal ' villi' (Fone and others, r 960; Rubin and others, I960a; Doniach and Shiner, I957). However, single histological sections of these mucosæ give a false impression, for what appear to be 'villi' are, in fact, transverse sections through the ridges shown in Fig. 6a, an appearance which the term 'convoluted 'seems best to describe. The threedimensional view obtained under the dissecting microscope reveals the nature of these pathological abnormalities more clearly and accurately than histological examination alone.

Although this convoluted type of mucosa appears entirely different from the 'flat' biopsies shown in Figs. $4^{a}$ and $5 \mathrm{a}$, the appearances of jejunal specimens from other patients suggest that they may be related. A ridged and convoluted mucosa is often arranged in a mosaic form similar to that in the 'flat ' mucosa shown in Fig. 5a. Furthermore, we have seen one biopsy taken from a patient with 


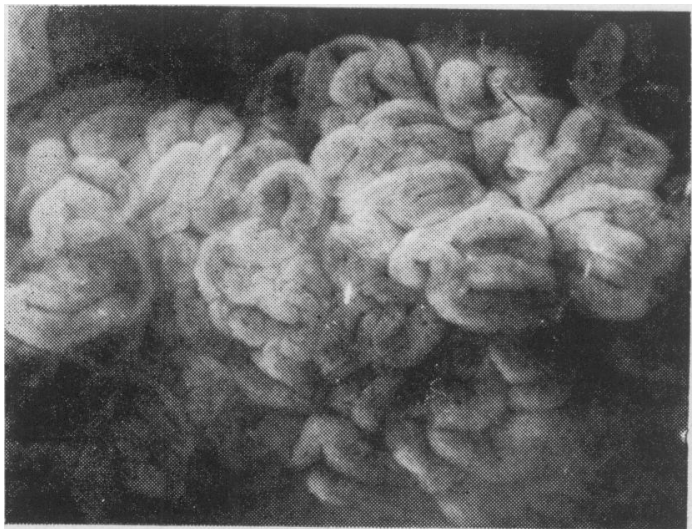

FIG. 6A.-Dissecting microscope appearance of jejunum showing ' convoluted' mucosa $(\times 25)$. The histological section of this specimen is shown in Fig. $6 \mathrm{~b}$.

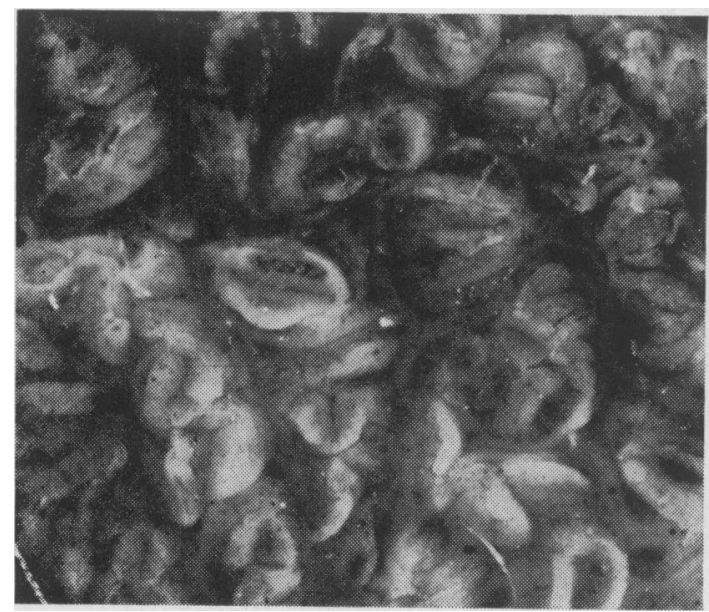

Fig. 7A.-Dissecting microscope appearance of ileum showing 'convoluted' mucosa ( $\times 30)$. The histological section of this specimen is shown in Fig. $7 \mathrm{~b}$.

adult cœliac disease who was responding well to a gluten-free diet in whom areas of entirely 'flat' mucosa alternated with a convoluted appearance.

Clinically, this 'convoluted' type of mucosa rarely occurs in patients with untreated cœliac disease. It is more commonly seen in adult patients suffering from latent idiopathic steatorrhœa who present with deficiency states such as megaloblastic anæmia or osteomalacia and who have minimal intestinal symptoms. This is not invariably the case, for we have encountered two adult patients with cœliac disease whose jejunal biopsies have shown the 'convoluted' appearance.

\section{Ileum}

Although the changes in the mucosa of the

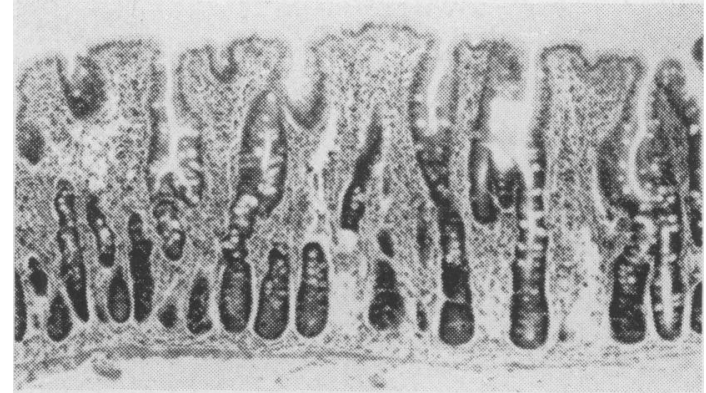

Fig. 6B.- - Histological section of jejunal mucosa shown in Fig. 6a.

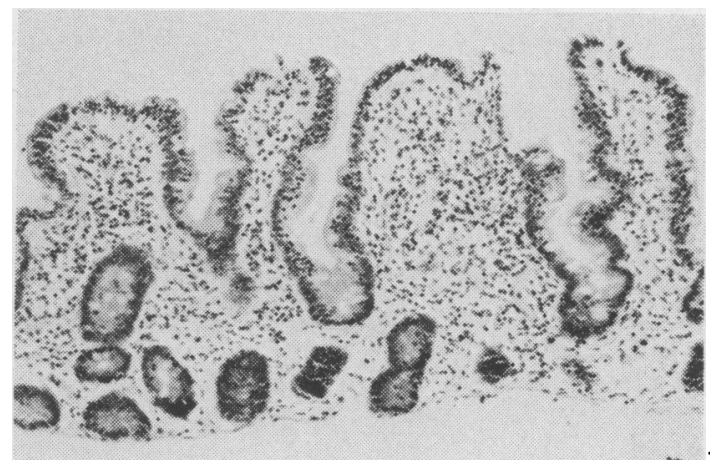

FIG. 7B.-Histological section of 'convoluted' ileak mucosa shown in Fig. 7a.

jejunum in coliac disease and idiopathic steatorrhœa have been well described, very much less is known of the pathology of the ileum. Rubin and his colleagues (1960a) have reported normal ileal histology in patients whose jejunal biopsies were ' $f$ lat', but in other instances ileal changes have been similar to those found in the jejunum (Shiner and Doniach, 1958; Mollin, Booth and Chanarin, 1958). We have had the opportunity of examining both jejunal and ileal mucosa in eight adult patients suffering from idiopathic steatorrhœa. The mucosal appearances in these patients are described in the accompanying table.

Four of these patients (Cases I to 4 ) had a ' flat' jejunal mucosa. In the first patient (Case I) it was possible to examine the entire intestinal tract at autopsy (Hourihane, Holmes and Booth, 196r). The ileum in this patient showed a predominantly ' convoluted' appearance, but the changes were undoubtedly patchy, for there were also areas where the ileal mucosa was entirely flat and other smaller areas which appeared normal. In the next two patients (Cases 2 and 3 ) ileal biopsies showed a ' convoluted' appearance. The advantage of examination under the dissecting microscope is illustrated by the ileal biopsy obtained 
TABLE

The Changes. in the Jejunum and Ileum in Eight Patients with IDiopathic SteatorRhoea

\begin{tabular}{|c|c|c|}
\hline Case & Jejunum & Ileum \\
\hline $\mathbf{I}$ & 'Flat' & $\begin{array}{l}\text { 'Flat', ' convoluted ' } \\
\text { and normal }\end{array}$ \\
\hline 2 & 'Flat' & 'Convoluted' \\
\hline 3 & 'Flat' & 'Convoluted' \\
\hline 4 & 'Flat' & Normal \\
\hline 5 & 'Convoluted' & Normal \\
\hline 6 & 'Convoluted' & Normal \\
\hline 7 & 'Convoluted', & Normal \\
\hline & Convoruted & Normal \\
\hline
\end{tabular}

from one of these patients (Case 3). On conventional histological examination (Fig. $7 \mathrm{~b}$ ) it might be difficult to determine the nature of the intestinal lesion, for almost normal 'villi' can be seen. Under the dissecting microscope, however, the characteristic ridged pattern of a 'convoluted' mucosa is seen (Fig. 7a). The fourth patient (Case 4) had a normal ileal biopsy.

The remaining four patients (Cases 5 to 8 ) had a 'convoluted' jejunal biopsy. The ileum was normal in all these four patients.

\section{Comment}

It is as yet uncertain whether the flat appearances shown in Figs. 4 and 5 represent a more severe degree of intestinal mucosal change than the ridged and convoluted abnormalities illustrated in Fig. 6a. That these changes may indicate differences in severity is best supported by the observation that areas of the ileum may show a convoluted appearance when the jejunum is entirely flat. The gradation of changes observed between an entirely convoluted and a flat mucosa is also in keeping with this hypothesis. The abnormalities range from a mucosa which is entirely flat at one end of the scale (Fig. 4a) to a flat mucosa arranged in a mosaic pattern (Fig. $5 \mathrm{a}$ ), then to a mosaic pattern in which there is a ridged and convoluted appearance and, finally, to an entirely convoluted mucosa at the other end of the scale (Fig. 6a). This last type of mucosa may well merge with the normal, for, as we have pointed out, apparently ridged areas may be seen in otherwise normal biopsies where there is a predominance of leaf-shaped villi, possibly by fusion of these villi.

What causes the mucosal changes in coliac disease and idiopathic steatorrhœa is not yet known. It has frequently been reported that jejunal biopsies show no improvement in many patients who respond satisfactorily to a gluten-free diet (Rubin, Brandborg, Phelps, Taylor, Murray, Stemler, Howry and Volwiler, 1960b), but more recent reports have indicated that jejunal histology may become normal on this regime. Anderson (1960), for example, has demonstrated marked im- provement in the duodenal biopsies of children with cœliac disease treated with the gluten-free diet, although it is uncertain whether their initially flat biopsies returned to an entirely normal villous mucosa. Zetterquist and Hendrix (1960) demonstrated regeneration of the epithelial microvilli using electron microscopy in two patients with idiopathic steatorrhœa after as little as four months on a gluten-free diet. These observations suggest that the intestinal mucosal abnormalities in patients who respond to this dietary regime are due to a toxic action of gluten. The finding of a normal or less severely abnormal mucosa in the ileum when the jejunum is severely abnormal is in keeping with the concept that a foodstuff is responsible for the mucosal changes. A crucial experiment which appears to clinch the hypothesis that gluten sensitivity is the cause of these changes has been carried out by Rubin and his colleagues (Rubin and others, 1960c; Rubin, Flick, MacDonald and Parmentier, 1961). These workers demonstrated the development of abnormalities in the ileal mucosa after instilling gluten directly into the ileum of cœliac patients whose distal intestine was initially histologically normal.

The nature of these changes is a matter for speculation. Although the term 'villous atrophy' is frequently used, there is no evidence that the 'flat ' mucosa is an atrophic process and it is difficult to conceive how atrophy might lead to the 'convoluted' appearance. Furthermore, as Doniach and Shiner (1957) have pointed out, the glandular layer of the mucosa is hypertrophied and thicker than normal. These observations have led to the suggestion that the increased mucosal thickness is due to compensatory hypertrophy of the glandular layer in an attempt to " maintain a villous epithelium intact in the face of the threatened lifespan of the cells ', a situation which is analogous to bone marrow hypertrophy in the presence of anæmia (Doniach and Shiner, 1960). This idea has recently been supported by Padykula and her colleagues (196r).

Further studies of jejunal and ileal histology are necessary to determine the variations in normal appearances and the cause and nature of the 'flat' and 'convoluted' mucosa. Although much remains to be learnt from further studies using conventional and electron microscopic techniques, it should be emphasized that the three-dimensional view of biopsy material obtained with a dissecting microscope may be of major importance in assessing changes in the shape and pattern of the villi. It also provides the most rapid method of diagnosis.

We wish to thank Mr. W. Brackenbury for the preparation of the photographs, and the Medical Research Council for their support. 


\section{REFERENCES}

Adlersberg, D., and Schein, J. (1947): Clinical and Pathological Studiès in Sprue, f. Amer. med. Ass., i34, 1459.

ANDERson, C. M. (1960): Histological Changes in Duodenal Mucosa in Cœliac Disease: Reversibility During Treatment with a Wheat Gluten-free Diet, Arch. Dis. Childh., 35, 419.

BaKER, S. J., and Hughes, A. (1960): Multiple-retrieving Small-intestinal Biopsy Tube, Lancet, ii, 686.

BrandborG, L. D., Rubin, C. E., and Quinton, W. E. (1959): A Multi-purpose Instrument for Suction Biopsy of the Esophagus, Stomach, Small Bowel and Colon, Gastroenterology, 37, 1 .

Brettauer, J., and Steinach, S. (1857): Untersuchagen uber das Cylinder-epithelium der Darmzotten und seine Bezielung zur Fettrosorption, S.B. Akad. Wiss. Wien, math.-nat. Kl., 23, 303.

Butterworth, C. E., Jr., and Perez-Santiago, E. (1958), Jejunal Biopsies in Sprue, Ann. intern. Med., 48, 8.

Bolt, R. J., Pollard, H. M., and Standaert, L. (1958): Transoral Small Bowel Biopsy as an Aid in the Diagnosis of Malabsorption States, New Engl. F. Med., 259, 32.

Crosby, W. H., and KugLER, H. W. (1957): Intraluminal Biopsy of the Small Intestine; the Intestinal Biopsy Capsule, Amer. Y. dig. Dis., 2, 236.

Culver, P. J., Benson, J. A., Strauss, E., and Jones, C. M. (1959): Some Observations on the Malabsorption Syndrome Based on Use of Absorption Tests and Biopsy of the Small Intestine, Gastroenterology, 36, 459.

Doniach, I., and ShINER, M. (1957): Duodenal and Jejunal Biopsies: II. Histology, Ibid., 33, 7 I.

- (1960): Histopathology of the Stomach in Pernicious Anæmia and Jejunum in Steatorrhoa, Brit. J. Radiol., 33, 238.

Flick, A. L., Quinton, W. E., and Rubin, C. E. (1961): A Peroral Hydraulic Biopsy Tube for Multiple Sampling at any Level of the Gastrointestinal Tract, Gastroenterology, 40, 120.

Fone, D. J., Cooke, W. T., Meynell, M. J., Brewer, D. B., Harris, E. L., and Cox, E. V. (1960): Jejunal Biopsy in Adult Coeliac Disease and Allied Disorders, Lancet, i, 933.

Girdwood, R. H., Delamore, I. W., and WynN Williams, I. (1961): Jejunal Biopsy in Malabsorptive Disorders of the Adult, Brit. med. F., ii, 319.

Hartman, R. S., Butterworth, C. E., Hartman, R. E., Crosby, W. H., and Shirai, A. (1960): An Electron Microscope Investigation of the Jejunal Epithelium in Sprue, Gastroenterology, 38, 506.

Haubrich, W. S., Watson, J. H. L., O'Driscol, W., and Valentine, V. (1959): Electron Microscopy of the Free Border of Human Intestinal Epithelial Cell, Henry Ford Hosp. Bull., 7, 113.

Holmes, R., Hourihane, O’B. D., and Booth, C. C. (196r): Dissecting Microscope Appearances of Jejunal Biopsy Specimens from Patients with Idiopathic Steatorrhœa, Lancet, i, 8I.

Hourihane, D. O'B., Holmes, R., and Booth, C. C. (1961): In preparation.

Manson-BAhR, P. (1915): 'A Report on Research on Sprue in Ceylon, 1912-14'. London: Cambridge University Press.

Molin, D. L., Booth, C. C., and Chanarin, I. (1958): ' The Pathogenesis of Deficiency of Vitamin $B_{12}$ and Folie Acid in Idiopathic Steatorrhœe', Proceedings of World Congress of Gastroenterology, Washington, 1958 . p. 483. Baltimore: Williams and Wilkins.

Paulley, J. W. (1954): Observations on the Ætiology of Idiopathic Steatorrhoa, Brit. med. F., ii, 1318.

Padykula, H. A., Strauss, E. W., Ladman, A. J., and Gardner, F. H. (1961): A Morphologic and Histochemical Analysis of the Human Jejunal Epithelium in Non-tropical Sprue, Gastroenterology, 40, 735.

Rubin, C. E., Brandborg, L. L., Phelps, P. C., and Taylor, H. C. (r960a): Studies of Coeliac Disease, I, Ibid., 38, 28.

, T , Murray, C. V., Stemler, R., Howry, C., and Volwiler, W. (1960b): Studies of Coliac Disease, II, Ibid., 38, 517 .

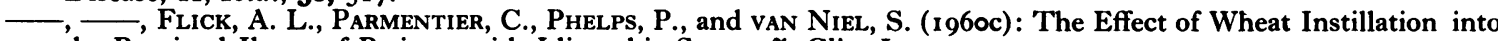
the Proximal Ileum of Patients with Idiopathic Sprue, $\mathcal{F}$. Clin. Invest., 39, 1023.

- Flick, F. L., MacDonald, W. C., and Parmentier, C. M. (1961): Acute Intestinal Response to Wheat in Coeliac Sprue, Clin. Res., 9, 89.

Sakula, J., and Shiner, M. (1957): Cœeliac Disease with Atrophy of the Small Intestine Mucosa, Lancet, ii, 876.

SHINER, M. (1956): Duodenal Biopsy, Ibid., i, 17.

and Doniach, I. (1958): 'Histopathologic Studies in Steatorrhøea'. In Proceedings of the World Congress of Gastroenterology, Vol. I, p. 580. Baltimore: Williams and Wilkins.

Smith, R. B. W., Sprinz, H., Crosby, W. H., and Sullivan, B. H. (1958): Peroral Small Bowel Mucosal Biopsy, Amer. F. Med., 25, 391.

Thaysen, T. E. H. (1932): ‘ Non-tropical Sprue’. London: Oxford University Press.

ZetTERQuist, H., and Hendrix, T. R. (1960): A Preliminary Note on an Ultra-structural Abnormality of the Intestinal Epithelium in Adult Coeliac Disease (Non-tropical Sprue) which is Reversed by a Gluten-free Diet, Bull. Yohns Hopk. Hosp., 106, 240. 